\title{
Face-saving Strategies in Responding to Gratitude Expressions: Evidence from Canadian English
}

\author{
Bernard Mulo Farenkia ${ }^{1}$ \\ ${ }^{1}$ Department of Languages and Letters, Cape Breton University, Canada \\ Correspondence: Dr. Bernard Mulo Farenkia, Department of Languages and Letters, Cape Breton University, \\ 1250 Grand Lake Road, Sydney, Nova Scotia, B1P6L2, Canada. E-mail: bernard_farenkia@cbu.ca
}

Received: May 22, 2012 Accepted: May 31, 2012 Online Published: June 20, 2012

doi:10.5539/ijel.v2n4p1 URL: http://dx.doi.org/10.5539/ijel.v2n4p1

\begin{abstract}
This study examines (politeness) strategies employed by a group of English-speaking Canadian University students when responding to gratitude expressions. Based on data collected by means of a Discourse Completion Task (DCT) questionnaire, the quantitative and qualitative study addresses functional, formal and situational aspects of responses to thanks. With regard to speakers' strategies, the study reveals that the participants mostly preferred "minimizing the favour" and "expressing appreciation" in their responses. This finding suggests that native speakers of Canadian English seem to make the same choice as speakers of Irish English, American English and British English. In terms of the realization forms of responses to thanks, the results indicate that the participants mostly employed constructions with no problem, welcome and pleasure. With regard to the length of responses, it was found that the informants favoured simple responses to thanks much more often than complex responses. Also, social and power distance was found to play a role in the choice of the semantic strategies and the realization forms as well as in the move-structure and the length of the responses.
\end{abstract}

Keywords: reponses to thanks, face, politeness, Canadian English, university students, discourse completion tasks

\section{Introduction}

It is very common to express gratitude for any type of help or verbal gifts (advice, compliments, offers, etc.). Responding to gratitude expressions is also a universal practice. However the strategies used to express appreciation and to respond to thanks are language and culturally specific. Even within the same language or cultural setting some differences emerge due to region, age, gender, social status, ethnicity, etc. The present study examines strategies used by native speakers of Canadian English when responding to expressions of gratitude.

A response to thanks follows a gratitude expression. In other words responding to thanks constitutes "a reactive interactional move which follows a reactive move, as the act of thanking also refers back to something else" (Schneider, 2005: 103). Expressions of gratitude are used "when a speaker wants the addressee to know that s/he is grateful for what the addressee has said or done.” (Jautz, 2008: 142). By expressing appreciation the speaker enhances the positive face of the addressee. Positive face is defined as "the want of every member that his wants be desirable to at least some others” (Brown \& Levinson, 1987: 62). Gratitude expressions are used to indicate that the speaker is appreciative for and approved of what the addressee has done. Hence, thanks and responses to thanks form dialogical units known as adjacency pairs. Although thanking is described as a face-enhancing, a convivial or a positively affective speech act (Leech 1983: 104), it is presented in Brown and Levinson's theory of face (1987: 67) as a face-threatening act and, more precisely an act of accepting a debt or an act of humbling the speaker's own face. Overall, when responding to gratitude expressions the respondent may address the following aspects. The addressee may either focus on the face-enhancing aspect of the appreciation token or feel obliged to minimize the speaker's indebtedness and "thus to restore the imbalance in the relationship between the interactants caused by the thankee's action in favour of the thanker” (Schneider, 2005: 107). The addressee may also combine both aspects in his/her response to the appreciation. (Note 1) The aspects on which the respondents lay emphasis certainly determine the types and length of the realization forms of responses to thanks. Using Brown and Levinson's (1987) framework, it is plausible to indicate that responses to gratitude expressions may target either the positive or the negative face of the speaker and/or the addressee. In other words, responses 
to thanks convey positive politeness and/or and negative politeness. It should be recalled that positive politeness is directed to the addressee's positive face and the strategies employed are "in many respects simply representative of the normal linguistic behavior between intimates, where interest and approval of each other's personality, presuppositions indicating shared wants and shared knowledge, implicit claims to reciprocity of obligation or to reflexivity of wants, etc." (Brown \& Levinson, 1987: 101). Negative politeness is directed to the addressee's negative face, i.e. "his want to have his freedom of action unhindered and his attention unimpeded" (Brown \& Levinson, 1987: 129). An analysis of the realization strategies of responses to gratitude expressions may reveal preferences in the politeness system of members of a linguistic and cultural community.

Many scholars have dealt with the realization forms of gratitude expressions and responses to thanks in languages such as Akan (Agyekum, 2010), English (Aijmer, 1996; Einstein \& Bodman, 1993), French (Kerbrat-Orecchioni, 2005; Lucie Bujon, 2008), German (Marten-Cleef, 1991), etc. Studies from a cross-cultural pragmatics perspective compare French and Italian (Held, 1995), German and Spanish (Sosa Mayor, 2006), German and Iraqi Arabic (Ali Mahdi, 2010). While the bulk of research done so far has focused on differences and similarities in the realization of these speech acts in different languages, some few scholars have focused their attention on regional varieties of pluricentric languages. As far as English as a pluricentric language is concerned, there have been some studies highlighting differences across national varieties of English. Such studies include Jautz's (2008) analysis of gratitude expressions in British and New Zealand English radio programmes and Elwood's (2010) examination of gratitude expressions in Irish English and New Zealand English. The few studies on responses to gratitude include Schneider's (2005) investigation of responses to thanks in three national varieties of English, namely the varieties spoken in Ireland, England and the United States of America. Based on data collected by means of Discourse Completion Tasks, the author identified similarities and differences between the three language varieties with regard to the following seven parameters: The interactional patterns in which the responses are employed, the realization of head moves and supportive moves, the types of response realizations and their variants, the frequencies of tokens belonging to these types, the speaker strategies, the modification patterns and the situational distribution of tokens (Schneider, 2005: 128). In terms of speaker strategies (conventions of means), the author found that "minimizing the favour" (strategy A) "is much more important for speakers of English English than for speakers of Irish English or American English [...]. By contrast, the Irish and American informants employed the strategy "expressing appreciation of the addressee” (strategy C) much more frequently than speakers of English English.” (Schneider, 2005: 129). Although Talla Sando Ouafeu's (2009) article examines responses to thanks in Cameroon English, the author implicitly compared his findings with strategies found in other varieties of English. For instance, he indicates that a large majority of the participants acknowledged thanking by saying "yes" and that "expression such as not at all, you are welcome,don't mention it, no problem, great pleasure which appear to be common in many varieties of English did not occur in the Cameroon interview data.” (Talla Sando Ouafeu, 2009: 547). According to the author, the strong preference for responses with "yes" in Cameroon English "may be a result of an underlyingly Cameroonian thanking routine carried out in English, as thanking is acknowledged in many Cameroonian local languages” (Talla Sando Ouafeu, 2009: 548). There seems to be no study on responses to thanks in Canadian English. Therefore, this paper aims to contribute to variational pragmatics, i.e. the study of intralingual pragmatic variation, and to cross-cultural pragmatics, the comparison of pragmatic phenomena across different languages. This introduction is followed by a discussion of the methodology (Section 2). The results of the study are presented and discussed in section 3.

\section{Methodology}

\subsection{Participants}

Sixty three students at the Cape Breton University (Canada), 21 (33.33\%) males and 42 (66.67\%) females, participated in the study. They ranged in age from 18 to 67 . More precisely, $57(90.48 \%)$ of the participants were in the age range between 18 and 24 and 6 (9.53\%) of the informants were between 25 and 67 years old. All the respondents were native speakers of Canadian English and were taking courses in degree programs in a range of disciplines offered by the institution (e.g. English, Communication, Business administration, Political science, History, Chemistry, Nursing, Anthropology, French, Engineering, Sociology, etc.).

\subsection{Instrument and Procedure}

For this study, we collected speech act data by means of a Discourse Completion Task (DCT) questionnaire consisting of tasks related to the production of speech acts such as apologies, requests, complaints, invitations, refusals, gratitude expressions, etc. The present study focuses on responses to thanks. Each situation comprised a brief description setting "the general circumstances [...] and the relevant situational parameters concerning 
social dominance, social distance and degree of imposition” (Barron, 2008: 43). The students had to write what they would say in response to gratitude expressions from a professor, a stranger and a close friend, as indicated in the descriptions below.

1) Your Professor asks you to help him/her organize a conference. After the event s/he calls you in his/her office and says "Thank you very much for your help last week". What would you say?

You :

2) A stranger got lost on campus. S/he asks you to take him/her to the university bookstore. When you get there s/he says "Thank you very much for your help". How would you respond?

You :

3) A close friend asks you to help type a paper. When the work is done, s/he says "thank you". What would you say?

You :

\subsection{Data Analysis}

The 63 informants provided 189 answers in which responses to thanks appeared as single head acts, as combinations of head acts, and as combinations of head acts and supportive moves. The responses were analyzed and defined in terms of the semantic strategies employed to react to expressions of gratitude. This aspect of the study was based on Aijmer's (1996) classification of responses to thanks (cf. section 4.1). The response strategies were also examined in terms of their linguistic realization forms. Using Schneider's (2005) inventory, it was noticed that the respondents used linguistic forms that could be classified in eight different sub-categories (cf. section 4.2). Another aspect of the analysis was to consider the directness or indirectness of the responses to thanks as well as their length. By length, we mean the number of strategies involved in a response (e.g. single, multiple (double, triple, etc.) and the strategy combinations involved: single head act, combinations of head acts, combinations of head acts and supportive moves (cf. section 4.3). Finally, the situational distribution of the major strategies and the linguistic realization forms were examined. The next section presents the results of the data analysis.

\section{Results}

\subsection{Conventions of Means}

According to Aijmer (1996), speakers employ the following five strategies to respond to thanks and to minimize the indebtedness of the thanker.

1) Strategy A: "Minimizing the favor". The thankee downplays the favour offered to the thanker or indicates that the action taken to do a favour to the other did not cause any trouble: e.g. No problem at all. Don't mention it. It is a negative politeness strategy.

2) Strategy B: "Expressing pleasure". The thankee says that he or she had pleasure in doing the other a favour: e.g. My pleasure. This is a positive politeness strategy that enhances the positive face of both the speaker and the addressee.

3) Strategy C: "Expressing appreciation”. The thankee expresses appreciation of the addressee: e.g. You are very welcome. It is positive politeness strategy.

4) Strategy D: "Returning thanks": the thankee thanks the addressee in return: e.g. Thank you too. This is positive politeness strategy.

5) Strategy E: “Acknowledging the thanks": the thankee indicates that he or she acknowledges the thanks: e.g. Yeah. It is a positive politeness strategy.

Table 1 presents the frequency of the five strategies in the corpus.

Table 1. Frequencies of the strategy types

\begin{tabular}{lll}
\hline Strategy types & Frequency: N and (\%) \\
\hline 1. Strategy A: "Minimizing the favour” & $123(50 \%)$ \\
2. Strategy B: “Expressing pleasure” & $34(13.82 \%)$ \\
3. Strategy C: "Expressing appreciation” & $77(31.30 \%)$ \\
4. Strategy D: "Returning thanks” & $9(3.66 \%)$ \\
5. Strategy E: “Acknowledging the thanks” & $3(1.22 \%)$ \\
Total & $246(100 \%)$ \\
\hline
\end{tabular}


As can be seen in Table 1 above, the most common strategy type was strategy A ("minimizing the favour") at $50 \%$ and the second most dominant strategy was strategy C ("expressing appreciation") at $31 \%$. Together, the two most preferred strategies by the participants accounted for more than $80 \%$ of all the responses. Strategy E ("acknowledging the thanks") was the least employed by the informants. Overall, negative politeness strategies and positive politeness strategies were equally distributed in the data. With regard to the use of strategies A and C and based on the findings of Schneider (2005: 121-122), we could say that the Canadian respondents seem to make the same choices as speakers of American English, Irish English and British English.

\subsection{Conventions of Form}

The strategies discussed in section 4.1 were also examined with regard to their linguistic realization forms. Using Schneider's inventory (2005: 116), we identified the following eight groups of realization forms No problem; Welcome; Pleasure; Anytime; Thanks; Don't worry about it; Yeah; Don't mention it. Some of these forms also appeared in various patterns. Table 2 below shows a breakdown of the realization forms and how they relate to the five major strategies of thanks minimizers.

Table 2. Frequency of the realization types

\begin{tabular}{|c|c|}
\hline \multirow{2}{*}{$\begin{array}{l}\text { Strategy types and realization forms } \\
\text { 1. Strategy A: "Minimizing the favour" }\end{array}$} & \multirow[t]{2}{*}{ Frequency: $\mathrm{N}$ and (\%) } \\
\hline & \\
\hline a. NO PROBLEM & $118(47.97 \%)$ \\
\hline b. DON'T WORRY ABOUT IT & $4(1.63 \%)$ \\
\hline c. DON'T MENTION IT & $1(0.40 \%)$ \\
\hline 2. Strategy B: "Expressing pleasure” & \\
\hline a. PLEASURE & $34(13.82 \%)$ \\
\hline 3. Strategy C: "Expressing appreciation" & \\
\hline a. WELCOME & $56(22.76 \%)$ \\
\hline b. ANYTIME & $21(8.54 \%)$ \\
\hline 4. Strategy D: "Returning thanks" & \\
\hline a. THANKS & $9(3.66 \%)$ \\
\hline 5. Strategy E: “Acknowledging the thanks" & \\
\hline a. YEAH & $3(1.22 \%)$ \\
\hline Total & 246 (100\%) \\
\hline
\end{tabular}

As can be seen in Table 2, the participants used a total of 246 tokens, which were realized in various ways.

3.2.1 Strategy A: "Minimizing the Favour"

Table 2 above shows that this strategy was realized by means of three different sub-strategies: No problem, Don't mention it and Don't' worry about it.

No problem, which came first at $47.97 \%$ (118 occurrences), was realized in the following ways: No problem, not a problem, no prob, no problem at all, that's no problem, it was no problem at all, it's no problem.

Don't worry about it occurred four times (1.63\%) and was realized as don't worry about it, no worries, while don't mention it appeared once (0.40\%) and was realized as don't mention it.

\subsubsection{Strategy B: "Expressing Pleasure"}

Pleasure was the third most frequent realization type in the data at $13.82 \%$ (34 instances). The respondents were very productive and creative in terms of the linguistic realization forms employed. They used short as well as expanded structures containing positively loaded adjectives such as glad, happy, pleased, nouns or noun groups such as pleasure, fun, reward, great time and/or the verb enjoy and adverbs of intensity such as really and so, as in the following examples: I'm glad that I could help, glad to help, I was glad to help you, glad I could help, happy to help, my pleasure, it was fun, it was my pleasure to be able to assist you, it was a reward in itself to be able to help someone, it was my pleasure, I'm glad I was of assistance, I had a great time doing it and I learned a lot, I had fun, I was only too glad to be able to help, I really enjoyed organizing this conference with you, I was so pleased to be asked to help, I enjoyed helping. 


\subsubsection{Strategy C: "Expressing Appreciation"}

This strategy was realized with two different sub-strategies: Welcome and Anytime. By using constructions of in welcome group, the second most common realization type in our corpus with 56 tokens (22.76\%), the thankee minimized the favor granted to the thanker by expressing appreciation. Overall, the respondents employed the following realization forms: you're / you are welcome, you're very welcome, welcome. The first realization form was the most preferred by the respondents.

As the fourth most common realization type, anytime appeared in 21 examples (8.54\%) and was realized as anytime, anytime man, anytime feel free to ask me, I'm always free, anytime you need help just ask, any time you need help again I would be happy to. As can be seen from the examples, this response type was employed to indicate that the person thanked was ready to help (again) anytime.

\subsubsection{Strategy D: "Returning the Thanks"}

Thanks was found in 9 (3.66\%) of the attested tokens. With the response, the thankee returned the thanks to his/her communicative partner. As the examples below show, the expression of gratitude in response to thanks was realized in different ways: a) thanks + naming the thankee (thank you), b) thank + naming the thankee + indicating the reason for the gratitude (thanks for the opportunity (to help), thank you for the opportunity, thank you for asking for my help, thanks for asking me, thank you for considering me).

\subsubsection{Strategy E: "Acknowledging the Thanks"}

Yeah was used three times (1.22\%) and was realized as yeah,

\subsection{Situational Distribution of Strategies and Realization Forms}

The distribution of the five response strategies (conventions of means) as well as their linguistic realization forms (conventions of forms) across the three situations was also examined. The results are summarized in Table 3 below.

Table 3. Situational distribution of realization types

\begin{tabular}{|c|c|c|c|c|}
\hline Strategy types and realization forms & Friend & Professor & Stranger & Total \\
\hline \multicolumn{5}{|l|}{ 1. Strategy A "Minimizing the favour" } \\
\hline a. No problem & 42 & 33 & 43 & 118 \\
\hline b. Don't worry about it & 2 & 1 & 1 & 4 \\
\hline c. Don't mention it & 1 & 0 & 0 & 1 \\
\hline \multicolumn{5}{|l|}{ 2. Strategy B “Expressing pleasure” } \\
\hline a. Pleasure & 8 & 20 & 6 & 34 \\
\hline \multicolumn{5}{|l|}{ 3. Strategy C "Expressing appreciation" } \\
\hline a. Welcome & 16 & 23 & 17 & 56 \\
\hline b. Anytime & 7 & 10 & 4 & 21 \\
\hline \multicolumn{5}{|l|}{ 4. Strategy D “Returning thanks” } \\
\hline a. Thanks & 0 & 9 & 0 & 9 \\
\hline \multicolumn{5}{|l|}{ 5. Strategy E “Acknowledging thanks” } \\
\hline a. Yeah & 1 & 1 & 1 & 3 \\
\hline Total & 77 & 97 & 72 & 246 \\
\hline
\end{tabular}

As indicated in Table 3 above, strategy A ("minimizing the favour") was mostly favoured as response to gratitude expressions from a close friend (45 occurrences out of 123 or $36.59 \%$ ) and a stranger (44 examples out of 123 or $35.77 \%)$. Within this category forms belonging to the no problem sub-category were by far the most preferred realization forms. The two peripheral forms mostly appeared in the friend situation. Strategy B ("expressing pleasure") was mostly used in responses to thanks from a professor (20 instances out of 34 or $58.82 \%$ ) and least employed to respond to gratitude expressions from a stranger (6 examples out of 34 or 17.65\%). Strategy C ("expressing appreciation") was most common in the professor situation (33 occurrences out of 77 or $42.86 \%$ ). Forms belonging to the welcome sub-category mostly appeared in responses to thanks from a professor (23 examples out of 56 or $41.07 \%$ ). The second realization form of the strategy C, anytime, was 
the least employed in the stranger situation. Also, the fact that 10 examples out of 21 were found in responses to thanks from a professor might be considered as a way to boost the student-professor relationship by indicating the readiness to help (again). The intent to maintain a good relationship may also explain the abundant use of realization patterns belonging to the welcome sub-category. Strategy D ("returning thanks") was exclusively employed in the professor situation. A look at the realization forms of this strategy shows that the respondents focused more on the act / action that lead to the thanks of the professor than on the gratitude expression itself. As a matter of fact, most of the examples attested were constructed according to the patter thank you + for $V$-ing (e.g. thank you for asking for my help). Hence, this type of "returning thanks" could also be interpreted as an initial expression of gratitude. The least employed strategy E (“acknowledging thanks") was equally distributed across the three situations. Overall, the participants produced more tokens in responses to thanks from a professor (97 examples out of 246 or 39.43\%) than in the two other questionnaire situations (77 instances out of 246 or $31.30 \%$ in the friend situation and 72 occurrences out of 246 or $29.27 \%$ in the stranger situation).

\subsection{Length of Responses}

\subsubsection{Simple Responses vs. Complex Responses to Thanks}

In responding to thanks some informants used one-move structures, i.e. simple responses as in (1) while others employed complex responses, consisting of at least two moves as in (2). Hence, the 189 examples collected were examined with respect to the number of moves involved in each response to thanks. The results of this analysis are summarized in Table 4.

1) It was no problem at all.

2) You're welcome. I was glad to help you. Have agreatday!

Table 4. Frequency of simple and complex responses

\begin{tabular}{llll}
\hline \multicolumn{2}{l}{ Types of responses } & Frequency: N and & (\%) \\
\hline 1. Simple responses & 105 & $(55.55 \%)$ \\
2. Complex responses & & & \\
a. Two-move responses & 69 & $(36.50 \%)$ \\
b. Three-move responses & 13 & $(6.88 \%)$ \\
c. Four-move responses & 2 & $(1.06 \%)$ \\
Total & & 189 & $(100 \%)$ \\
\hline
\end{tabular}

Table 4 indicates that simple responses were by far the most frequently employed response type. The simple responses occurred in 105 instances (55.55\%). The complex responses consisted of two moves, as in (3), three moves, as in (4) or four moves, as in (5). The two-move responses, found in 69 instances (36.50\%) of the corpus, were the most preferred complex responses. The four-move responses, the least represented type, were found in 2 instances (1.06\%).

3) No problem! Hope it's what you were looking for.

4) Anytime, not a problem! Glad to help.

5) Don't worry about it. I don't mind helping and anyways it was fun. Also, I learned a few new things which never hurts.

The distribution of the simple responses and complex responses across the three situations is summarized in Table 5.

Table 5. Situational distribution of simple responses and complex responses

\begin{tabular}{rlllll}
\hline & & Friend & Professor & Stranger & Total \\
\hline 1. & Simple responses & 38 & 27 & 40 & 105 \\
2. & (Total \# of) complex responses & $(25)$ & $(36)$ & $(23)$ & $(84)$ \\
a. Two-move responses & 22 & 28 & 19 & 69 \\
b. Three-move responses & 1 & 8 & 4 & 13 \\
c. Four-move responses & 2 & 0 & 0 & 2 \\
Total & & 63 & 63 & 63 & 189 \\
\hline
\end{tabular}


As can be seen in Table 5, the simple responses mostly appeared in the stranger situation, in a percentage of $38.09 \%$ (40 occurrences), while 38 instances (36.19\%) and 27 examples (25.71\%) of simple responses were used to respond to thanks from a friend and from a professor respectively. The two-move responses were mostly (28 examples or $40.58 \%$ ) used in responses to gratitude expressions from a professor. In the friend and stranger situations, the two-move responses occurred in 22 occurrences (31.88\%) and 19 instances (27.54\%) respectively. The respondents displayed a stronger preference for the three-move responses in the professor situation (8 tokens out of 13 or $61.54 \%$ ). The two four-move responses in the data were used in the friend situation. While the frequency of the simple responses was higher than that of the complex responses in the friend (simple responses 38 vs. complex responses 25 ) and stranger (simple responses 40 vs. complex responses 23) situation, it was the opposite in the professor situation where more complex responses occurred than simple responses (36 vs. 27).

\subsubsection{Types of Moves in Responses to Thanks}

The study also dealt with the question whether the moves in the simple responses and the complex responses were realized directly or indirectly. It was found that the responses to thanks in simple responses were either direct (direct head) or indirect (indirect head), while the responses to thanks in the complex responses consisted of either combinations of head acts or combinations of head act(s) and supportive move(s). In other words, the following three strategies were identified in the data: a) "head act(s) only"; b) "head act(s) + supportive move(s)"; c) "supportive move(s) only". It should be recalled that the head acts are "realized by standard tokens usually listed for illustration in the literature, i.e. formulaic expressions such as not at all, that's all right, or don't mention it." (Schneider, 2005: 113) (Note 2) Table 6 presents the breakdown of the move structures used by the participants to respond to thanks.

Table 6. Frequency of move structures used in responses to thanks

\begin{tabular}{lllll}
\hline & Friend & Professor & Stranger & Total \\
\hline Head act(s) only & 50 & 55 & 49 & $154(81.48 \%)$ \\
Head act(s) + supportive move(s) & 12 & 8 & 14 & $34(17.99 \%)$ \\
Supportive move(s) only & 1 & 0 & 0 & $1(0.53 \%)$ \\
Total & 63 & 63 & 63 & $189(100 \%)$ \\
\hline
\end{tabular}

Overall, "head acts only" was by far the most preferred realization pattern (81.48\%), while "supportive move only" was the least frequently used pattern. Also, "head acts only" was mostly used in the professor situation (35.71\%).

\subsubsection{Head Acts}

The analysis of the "head act only" strategies found in the data revealed that the respondents made use of single head acts as in (6) and multiple head acts (combinations of two head acts, as in (7) and three head acts, as in (8)). The result is summarized in Table 7.

6) No prob.

7) Not a problem. Thank you for considering me.

8) Yeah, no problem. It was my pleasure.

Table 7. Situational distribution of single heads and multiple head acts

\begin{tabular}{lllll}
\hline & Friend & Professor & Stranger & Total \\
\hline Single head acts & $38(76 \%)$ & $26(47.27 \%)$ & $43(87 \%)$ & $107(69.48 \%)$ \\
Double head acts & $11(22 \%)$ & $25(45.46 \%)$ & $5(10.20 \%)$ & $41(26.62 \%)$ \\
Triple head acts & $1(2 \%)$ & $4(7.27 \%)$ & $1(2.04 \%)$ & $6(3.90 \%)$ \\
Total & $50(100 \%)$ & $55(100 \%)$ & $49(100 \%)$ & $154(100 \%)$ \\
\hline
\end{tabular}

Table 7 shows that single head acts were the most frequently employed patterns (69.48\%) in the realization of the "head acts only" strategy, while multiple head acts occurred less frequently at $30.52 \%$. A breakdown of the multiple head acts also shows that double head acts were much more preferred than the triple heads. The distribution of these patterns across the three situations reveals that single head acts appeared most frequently in responses to thanks from a stranger at $40.17 \%$ of all attested single head acts, while the multiple head acts were most common in the professor situation (29 instances out of 47 or $61.70 \%$ of all multiple heads). This dominance 
of multiple head in the professor situation may be due to need to intensify responses to thanks from a communicative partner of a higher social status.

\subsubsection{Supportive Moves}

As already mentioned, some responses to thanks consisted of combinations of head acts and supportive moves. Overall, nine different supportive moves were used by the participants. The supportive moves appeared in 44 instances, as can be seen in Table 8 .

Table 8. Frequency of supportive moves

\begin{tabular}{lllll}
\hline Supportive moves & Friend & Professor & Stranger & Total \\
\hline Comment & $7(43.75 \%)$ & $6(60 \%)$ & $2(11.11 \%)$ & $15(34.09 \%)$ \\
Offering further help & $3(18.75 \%)$ & $4(40 \%)$ & $2(11.11 \%)$ & $9(20.45 \%)$ \\
Wish / hope & $2(12.50 \%)$ & 0 & $3(16.67 \%)$ & $5(11.36 \%)$ \\
Parting & 0 & 0 & $5(27.77 \%)$ & $5(11.36 \%)$ \\
Empathy & 0 & 0 & $6(33.34 \%)$ & $6(13.64)$ \\
Request & $2(12.50 \%)$ & 0 & 0 & $2(4.54 \%)$ \\
Joke & $1(6.25 \%)$ & 0 & 0 & $1(2.72 \%)$ \\
Promise & $1(6.25 \%)$ & 0 & 0 & $1(2.72 \%)$ \\
Suggestion/advice & 0 & 0 & $1(5.55 \%)$ & $1(2.72 \%)$ \\
Total & $16(100 \%)$ & $10(100 \%)$ & $18(100 \%)$ & $44(100 \%)$ \\
\hline
\end{tabular}

The supportive moves appeared in very rare occasions in lieu of the head acts. The respondents mostly combined the supportive moves with the head acts. Table 8 shows that some supportive moves did not occur in all the three situations. Six types were found in the stranger and in the friend situation and only two types were used in responses to thanks from a professor. The three most preferred supportive moves were comment (15 occurrences or 34.09\%), offering further help (9 examples or 20.45\%), and parting (5 instances or $11.36 \%$ ). Overall, the supportive moves were used to intensify the positive or negative politeness expressed in the head acts, as shown in the following discussion.

Comment: This supportive accompanied mostly responses to thanks from a friend (43.75\%) and from a professor (60\%). It was the third most favoured supportive move in responses to gratitude expressions from a stranger (11.11\%). The informants employed comments to intensify the negative politeness in strategy A ("Minimizing the favour"), as in (9) and (10), to reinforce the positive politeness in strategy B ("Expressing pleasure"), as in (11) and (12), in strategy C ("Expressing appreciation"), as in (13) and (14), and in strategy D ("Returning thanks") as in (15).

9) Not a problem at all. I love to help.(Note 3)

10) Don't worry about it. I don’t mind helping and anyway it was fun. Also, I learned a few new things which never hurts.

11) It was my pleasure. I learned a lot!

12) I was glad to help. That's what friends are for, to lend a helping hand.

13) You're very welcome. It was a good learning experience. I think it went very well.

14) You're welcome. The conference was interesting and helping organize it was a great experience. Thank you for asking for my help.

15) Thank you. It was a great experience.

Offering help: As indicated in table 8, this supportive move mostly accompanied responses to thanks from a professor. With this strategy, the speaker indicated their readiness to help (again) in the near future. As solidarity markers offers were employed to intensify A ("Minimizing the favour"), as in (16), strategy B ("Expressing pleasure”), as in (17), and strategy C ("Expressing appreciation”), as in (18). A striking feature of this supportive move was the use of the conditional if, which, according to Barron (2005: 161), could be interpreted as a face-saving strategy: "by communicating that the speaker does not expect the hearer to [accept] the offer unless $\mathrm{s}$ /he wants to, the speaker gives the hearer 'a real out' [...]. In other words, the force of a particular offer is mitigated by underlining its conditional nature”. 
16) Oh, it was no problem at all! I had fun. If you ever need help with anything else let me know.

17) I was so pleased to be asked to help. Please call on me if you think I may be able to help again.

18) You're welcome. I'm here if you ever need help.

Wish/hope. One participant expressed the wish that something good would happen to the thanker (19). Another informant expressed hope that the thanker was satisfied with the help rendered to him/her (20).

19) You're welcome! I hope you find everything you need!

20) No problem! Hope it's what you were looking for.

Empathy. This supportive move was exclusively employed in responses to thanks from a stranger. The function of this strategy was to assert reciprocity with the other. In three examples the speaker indicated that s/he understood how the addressee felt, as in (21) and (22).

21) No problem. I completely understand how you felt. This place was like a maze when I started here.

22) I know how it feels to be lost on this campus; glad to help!

In the other three examples the speaker narrated a similar experience as an attempt to minimize any feeling of embarrassment or any face loss due to the service rendered or the situation in which the stranger found him/herself, as shown in the examples below.

23) You're welcome. I got lost my first week here.

24) That's no problem. I got lost a few times too.

Joking. This supportive move was used to tease the addressee and to claim common ground.

25) You owe me. Just joking, no problem

Parting. Some participants used this external modification device to close the exchange by indicating the other as a potential partner in the future, as in (26), or by wishing the addressee to have a great day, as in (27) and (28)

26) No problem. See you later.

27) You're welcome. Take care.

28) No problem! Have a good/great day.

Request. One informant employed a request for help, as in (29), another used a promise to respond to a gratitude expression, as in (30). The last supportive move, suggestion/advice, was intended to indicate another source of help, if the other appeared not to be satisfied with the speaker's action, as in (31).

29) No problem. Now you can help me with mine.

30) You get the next one.

31) Anytime! Also, the Student's Union is right up that elevator, so if you need anything else they can point you in the right direction.

\section{Conclusion}

The purpose of this study was to examine strategies employed by a group of native speakers of Canadian English when responding to gratitude expressions. Using the classification of Aijmer (1996), we found that the participants employed five different strategies, of which strategy A ("Minimizing the favour") was by far the most frequently employed and strategy C ("Expressing appreciation") the second most common strategy in the data. This finding seems to indicate that Canadian English speakers make the same choice as speakers of American English, Irish English and British English when responding to thanks. In terms of the realization forms (conventions of forms), it was found that the participants made use of a considerable number of linguistic realization forms. In this respect, the three major realization types were, in decreasing order, No problem (118 instances or $47.97 \%$ ), Welcome (56 examples or 22.76\%) and Pleasure (34 occurrences or $13.82 \%$ ). The realization forms of Pleasure were the most varied in the data. With regard to the length of the attested responses, the analysis revealed the use of constructions with head acts only as well as combinations of head acts and supportive moves. The vast majority of the head acts only constructions contained single head acts (105 examples or 55.55\%). Overall, the nine different supportive moves accompanying the head acts were employed to intensify the negative and/or positive politeness expressed in the head acts. Comments were the most frequently used supportive moves in responding to thanks. Social and power distance was also found to play a role in the choice of semantic strategies and the realization forms. For example, the most frequently employed strategy in the data ("minimizing the favour") mostly appeared in responses to gratitude expressions from a close 
friend (45 occurrences out of 123 or 36.59\%) and a stranger (44 examples out of 123 or 35.77\%), while the second most preferred strategy (“expressing appreciation”) was most common in the professor situation (33 occurrences out of 77 or $42.86 \%$ ).

The results of this study may not represent what speakers of Canadian English would actually (i.e. in face-to-face situations) say when responding to thanks. Future further investigations based on other types of data (e.g. naturally occurring conversations) will certainly deepen or even contradict some of the findings of the present study. Also, there is need for comparative studies with other varieties of English and other languages in order to highlight cross-cultural and cross-linguistic differences. In this respect, the present study is a contribution to the growing body of research in regional pragmatic variation in pluricentric languages in general and in English in particular.

\section{Acknowledgements}

I would like to thank the Office of Research and Graduates at Cape Breton University for funding this research. Many thanks go to the students at Cape Breton University who participated in this study and my research assistant who helped me with data collection and processing.

\section{References}

Agyekum, K. (2010). The Sociolinguistics of Thanking in Akan. Nordic Journal of African Studies, 19(2), 77-97.

Aijmer, K. (1996). Conversational Routines in English. Convention and Creativity. London \& New York: Longman.

Ali Mahdi, H. (2010). Die RoutineformelnimDeutschen und imIrakisch-ArabischenEineempirische Untersuchung. Ph.D. Thesis, Philipps-University, Marburg.

Barron, A. (2005). Offering in Ireland and England. In A. Barron \& K. P. Schneider (Eds.), The pragmatics of Irish English (pp. 141-176). Berlin/New York: Mouton de Gruyter. http://dx.doi.org/10.1515/9783110898934.141

Barron, A. (2008). The structure of requests in Irish English and English. In K. P. Schneider \& A. Barron (Eds.), Variational Pragmatics. A Focus on Regional Varieties in Pluricentric Languages (pp. 35-67). Amsterdam/Philadelphia: John Benjamins.

Brown, P. \& Levinson, S. C. (1987). Politeness: Some Universals in Language Usage. Cambridge: Cambridge University Press.

Bujo, L. (2008). Les rituels de la politesse: analyse pragmatique des interactions lors de l'offre d'un cadeau. Thèse de doctorat, Université Lumière 2.

Eisenstein, M. \& Bodman, J. (1993). Expressing gratitude in American English. In G. Kasper \& S. Blum-Kulka (Eds.), Interlanguage Pragmatics (pp. 64-81). Oxford: Oxford University Press.

Elwood, K. (2010). An analysis of expressions of gratitude in Irish English and New Zealand English. The Cultural review, 36, 109-153.

Held, G. (1995). VerbaleHöflichkeit. StudienzurlinguistischenTheorienbildung und empirischeUntersuchungzum Sprachverhaltenfranzösischer und italienischerJugendlicher in Bitt- und Danksituationen. Tübingen: Narr.

Jautz, S. (2008). Gratitude in British and New Zealand radio programmes. Nothing but gushing? In K. P. Schneider \& A. Barron (Eds.), Variational Pragmatics. A Focus on Regional Varieties in Pluricentric Languages (pp. 141-178). Amsterdam/Philadelphia: John Benjamins.

Kerbrat-Orecchioni, Catherine (2005). Les actes de langage dans le discours. Paris: Armand Colin.

Marten-Cleef, S. (1991). Gefühleausdrücken. Die expressiven Sprechakte. Göppingen: Kümmerle Verlag.

Mayor, I. S. (2006). RoutineformelnimSpanischen und imDeutschen. Einepragmalinguistischekontrastive Analyse. Wien: Praesens Verlag.

Schneider, K. P. (2005). No problem, you're welcome, anytime. Responding to thanks in Ireland, England, and the USA. In A. Barron \& K. P. Schneider (Eds.), The pragmatics of Irish English (pp. 101-139). Berlin/New York: Mouton de Gruyter. http://dx.doi.org/10.1515/9783110898934.101

Talla Sando Ouafeu, Y. (2009). Thanking responders in Cameroon English. World Englishes, 28(4), 544-551. http://dx.doi.org/10.1111/j.1467-971X.2009.01611.x 


\section{Notes}

Note 1. There are different strategies for doing so and according to Schneider (2005: 106-107), the strategies employed may focus on the thankable, the thankee or the thanker.

Note 2. See also Aijmer (1996: 40).

Note 3 . The supportive moves in the examples are underlined. 